\title{
The relationship between behavioural and mood responses to monetary rewards in a sample of students with and without reported pain
}

\author{
Tanya Tandon (10 ${ }^{1 凶}$, Katharina Ledermann ${ }^{1,2}$, Rashmi Gupta ${ }^{3}{ }^{3}$, Naser Morina ${ }^{2}$, Dany Laure Wadji?, \\ Mayron Piccolo ${ }^{1,4} \&$ Chantal Martin-Soelch ${ }^{1}$
}

Pain impairs reward processing, and people suffering from physical pain are at high risk of having a persistently low mood. Although individuals with chronic pain have reported reduced reward responsiveness and impaired mood, it is not clear if reward responsiveness and mood are impaired in samples with sub-clinical pain scores otherwise healthy. Investigating a subclinical group is essential to disentangle the influence of medication on the behavioural effect of reward on mood and performance. Here, we aimed to examine the effects of reward on mood and performance in a sample of university students divided into a control group without clinically significant pain symptoms $(N=40)$ and the sub-clinical group with significant pain symptoms $(N=39)$. We used the Fribourg reward task and the pain sub-scale of the Symptom Checklist (SCL-27-plus) to assess the physical symptoms of pain. A significant positive correlation was found between average mood ratings and average monetary reward in the control group $\left(r_{38}=0.42, p=0.008\right)$ and not significant in the sub-clinical group $\left(r_{37}=0.12, p=0.46\right)$. The results might yield first insights into the relationship between pain and reward in sub-clinical populations without the confound of medication.

\footnotetext{
${ }^{1}$ Unit of Clinical and Health Psychology, University of Fribourg, Fribourg, Switzerland. ${ }^{2}$ Department of Consultation-Liaison-Psychiatry, University Hospital Zurich, University of Zurich, Zurich, Switzerland. ${ }^{3}$ Cognitive and Behavioural Neuroscience Laboratory, Department of Humanities and Social Sciences, Indian Institute of Technology Bombay, Mumbai, India. ${ }^{4}$ Department of Psychology, Harvard University, Cambridge, USA. ${ }^{凶}$ email: tanya.tandon@unifr.ch
} 


\section{Introduction}

n everyday life, a reward describes any event or object that can produce a positive or pleasurable experience (White, 2011; Gupta, 2019, for a review). Rewards effectively motivate people (Murayama, 2019) and involved in learning processes (Hidi, 2016; Gupta et al., 2019).

Pain and reward have been shown to interact (Gandhi et al., 2013). The interaction between reward and pain is conceptualized in Field's (2006) motivation-decision model. In this model, when both pain and reward are presented simultaneously, the brain is presented with a need to decide between pain or reward depending upon the individual's (homoeostatic) state and the magnitude of the potential threats and rewards. The effect of pain on reward processing has been confirmed experimentally in humans (Becker et al., 2013). For example, individuals with chronic pain reported a decreased response to environmental incentives and reduced reward responsiveness to monetary reward via self-report questionnaires (Liu et al., 2019). An experimental study conducted using the Behaviour Inhibition Scale/Behaviour Activation Scale to assess the reward drive and reward responsiveness showed that reward responsiveness is reduced in individuals with chronic pain (Turner et al., 2021). Another study used a monetary incentive delay task and functional magnetic resonance imaging on 17 female individuals with fibromyalgia to understand the neural processing of reward in chronic pain; this study showed that the individuals with chronic pain reported lower arousal ratings and showed reduced medial prefrontal cortex activity during monetary reward anticipation, which is related to lower estimated reward, in comparison to healthy controls (Martucci et al., 2018). The previous studies indicate that pain impairs reward processing (Becker et al., 2012; Gandhi et al., 2014).

Chronic pain is highly comorbid with mood disorders (Salazar et al., 2013). People suffering from physical pain are at high risk of having persistently low mood (Bair et al., 2003; Dersh et al., 2002). Furthermore, while winning rewards such as money is associated with increase in mood as evidenced in several studies using behavioural reward tasks in healthy control samples (Piccolo et al., 2019; Kalebasi et al., 2015; Martin-Soelch et al., 2009) an impaired mood responsivity to reward has been shown in individuals with chronic pain (Rizvi et al., 2021). For instance, a study conducted on individuals with chronic pain $(N=28)$ and healthy controls $(N=18)$ using the Monetary Incentive Delay (MID) task reported reduced neural responses to reward in the chronic pain group compared to healthy controls in regions associated with the cerebral reward system (Kim et al., 2020). Indeed, several studies support the presence of dysfunctional reward pathways in co-occurring pain and mood alterations (Berger et al., 2014; Treadway and Zald, 2011), suggesting reward processing could be a mechanism underlying the relationship between pain and mood disorders (Garland, 2020; Ledermann and Martin-Sölch 2018; Leknes and Tracey, 2008) and increase in mood have been correlated to neural changes in regions associated with the processing of reward (Martin-Soelch et al., 2003).

Given the observed relationship between pain and reward processing, it is interesting to further explore these interactions in a population with sub-clinical pain. This would allow to disentangle the influence of medication on the behavioural effect of reward on mood and performance. Therefore, in the present study, we investigated the relationship between behavioural and mood responses to monetary rewards between subjects reporting clinically significant pain symptoms (i.e., pain scores above the clinical threshold) and a control group not reporting clinically significant pain in everyday life. Based on the findings that painrelated impairments in reward processing were evidenced in clinical patients (Ledermann et al., 2017), we hypothesized that participants with sub-clinical pain scores would display a reduction of the effect of monetary reward on mood when compared to the participants without any clinically significant physical pain symptoms of pain. To test that, we used a validated spatial delay task that had successfully differentiated mood responses between sub-clinical and control samples in previous studies (Kalebasi et al., 2015; Martin-Soelch et al., 2009). Since monetary reward has been shown to have positive effects on performance and self-reported mood in healthy participants (Martin-Soelch et al., 2003, 2009), we expected a significant association between momentary mood ratings defined as the current subjective feeling of wellbeing (Martin-Soelch et al., 2009) and monetary winnings in the control group. The reward task was used to measure reward functioning (Gaillard et al., 2019). We also investigated whether task difficulty influences the interaction between mood, reward and performance, since previous studies (Martin-Soelch et al., 2009d) showed that task difficulty strongly affects reward processing. We included a task with different levels of difficulty (low and high) in order to test the relationship between reward, levels of difficulty, and performance. We divided the participants into two groups (sub-clinical group; participants with clinically significant pain symptoms and the control group) as we aimed to replicate the effects of reward on mood and performance and understand the associations of these effects expressed in the two groups.

\section{Methods}

Participants. Participants were recruited through flyers at the University in Switzerland. Each participant was screened for the exclusion and inclusion criteria using a short structured clinical screening based on the DSM-5 (American Psychiatric Association, 2013) criteria for the most frequent mental disorders. General exclusion criteria included current or past depression and history of psychiatric disorder as tested with the structured interview based on the M.I.N.I (Sheehan et al., 1998), use of any psychopharmacological medication and having a score $\geq 11$ on the Hospital Anxiety and Depression Scale (Bocéréan and Dupret, 2014). A total of 100 participants were recruited in our study of whom 79 were included as 21 participants were excluded because they had a score $\geq 11$ at the Hospital Anxiety and Depression scale (Bocéréan and Dupret, 2014) in order to avoid an effect of significant anxiety symptoms on reward as anxiety was shown to affect reward reaction (Mikita et al., 2016) and is often associated with pain (Gravani et al., 2021). The 79 remaining participants were then divided into two groups: of subclinical pain group and a control group. The criterion to be included in the sub-clinical pain group was to have a score above the clinical cut-off of 1.77 on the pain subscale based on the manual of Symptom Checklist-27-plus (Hardt, 2008). The cut-off is the official cut-off specified in the manual. The type of effect size used in our study is Partial eta squared $\left(\eta_{\mathrm{p}}^{2}\right)$ that is estimated to be 0.027 on the basis of the similar study by Kim et al. (2020) which investigated differences in mood and behavioural responses to reward between chronic pain patients and healthy controls using an ANOVA. We used the recommendations formulated by Lakens (2013) to enter the parameters in G-Power using a partial eta squared $\left(\eta^{2}\right)$ of 0.027 that led to the estimated Cohen's $F$ value of 0.17 . Using G-Power, the estimated sample size needed would be 80 to have the actual power with $5 \%$ alpha error, $95 \%$ power, and $p<0.05$ as the significance level for the ANOVA with repeated measures and within-between interaction.

The study was approved by the internal review board (2017/IRB 334A) at the Department of Psychology at the University. The participants were thoroughly informed about the study and gave their written consent. All research was performed in accordance with the Declaration of Helsinki. The privacy rights of participants were always observed during our study. 
Table 1 Participants' sociodemographic characteristics and clinical scores $(N=79)$.

\begin{tabular}{|c|c|c|c|c|c|c|c|c|c|c|}
\hline & \multicolumn{4}{|c|}{ Sub-Clinical Group $(N=39)$} & \multicolumn{4}{|c|}{ Control group $(N=40)$} & \multicolumn{2}{|l|}{ Statistics } \\
\hline Gender & & & & & \multicolumn{4}{|c|}{$35(44.3 \%)$} & \multirow{2}{*}{$\chi^{2}=0.44$} & \multirow{2}{*}{0.235} \\
\hline Male & \multicolumn{4}{|c|}{$\begin{array}{l}37(46.8 \%) \\
2(0.025 \%)\end{array}$} & $5(0.06$ & & & & & \\
\hline \multicolumn{11}{|l|}{ Language } \\
\hline French & \multicolumn{4}{|c|}{35 (89.7\%) } & \multicolumn{4}{|c|}{$30(75 \%)$} & \multirow{3}{*}{$t_{(64)}=2.35$} & \multirow[t]{3}{*}{0.189} \\
\hline \multirow{2}{*}{ Other } & \multicolumn{4}{|c|}{$4(10.3 \%)$} & \multicolumn{4}{|c|}{$10(25 \%)$} & & \\
\hline & \multicolumn{4}{|c|}{ Mean (SD) } & \multicolumn{4}{|c|}{ Mean (SD) } & & \\
\hline Age & \multicolumn{4}{|c|}{$24.5(9.17)$} & \multicolumn{4}{|c|}{$23.5(3.88)$} & \multirow[t]{2}{*}{$t_{(77)}=0.75$} & \multirow[t]{2}{*}{0.457} \\
\hline Psychometric measures & Mean & SD & Min. & Max. & Mean & SD & Min. & Max. & & \\
\hline HADS (Anxiety) & 12.33 & 4.56 & 0 & 20 & 12.25 & 5.75 & 0 & 19 & $t_{(73)}=0.368$ & 0.714 \\
\hline SCL-27-plus & 1.20 & 0.72 & 0 & 2.60 & 1.22 & 0.93 & 0 & 3.40 & $t_{(68)}=0.363$ & 0.718 \\
\hline Socio-phobic symptoms & & & & & & & & & & \\
\hline SCL-27-plus - Vegetative symptoms & 0.76 & 0.58 & 0 & 2.20 & 0.70 & 0.55 & 0 & 1.80 & $t_{(68)}=0.527$ & 0.600 \\
\hline Muscle Cramps & 1.92 & 1.15 & 0 & 4 & 0.83 & 0.75 & 0 & 2 & & \\
\hline Muscle Pain/Sore Muscles & 1.89 & 0.94 & 0 & 4 & 0.83 & 0.75 & 0 & 2 & & \\
\hline Pain in Arms or legs & 1.28 & 0.86 & 0 & 4 & 0.31 & 0.53 & 0 & 2 & & \\
\hline Backaches & 2.53 & 0.91 & 1 & 4 & 1.02 & 0.86 & 0 & 3 & & \\
\hline $\begin{array}{l}\text { SCL-27-plus - Lifetime assessment for } \\
\text { depressive symptoms }\end{array}$ & 1.3 & 0.33 & 1 & 2 & 1.23 & 0.33 & 1 & 2 & $t_{(73)}=0.958$ & 0.342 \\
\hline
\end{tabular}

Of the 79 participants included in this study, all were bachelor psychology students ${ }^{1}$ aged between 18 and 55 years $(M=23.98$ years, $\mathrm{SD}=6.98$ years), $72(91.1 \%)$ were women, and $82.2 \%$ were native French speakers or spoke French fluently. Participants were categorized into a group of 39 participants (37 women; $M=24.5, \mathrm{SD}=9.17)$ who reported physical symptoms of pain and a control group of 40 participants (35 women; $M=23.5$, $\mathrm{SD}=3.88$ ) with no clinically significant physical symptoms of pain (shown in Table 1).

\section{Procedure}

Fribourg reward task. We used an adapted behavioural version of the reward task (Martin-Soelch et al., 2009), Fribourg Reward Task, to measure reaction times, accuracy, and mood reactions to reward. Neuroimaging studies using this task have successfully elicited neural activation in regions associated with the cerebral reward system (Gaillard et al., 2019), including the striatum, a crucial cerebral region for reward processing. The task was programmed using E-Prime software (version 1.1.3, Psychology Software Tools Inc., Pittsburg, PA, USA) and presented on a high-resolution colour monitor. The monitor's resolution was $1024 \times 768$ pixels, and the presentation of the stimuli was synchronized with the refresh rate of the monitor. The display was viewed from a distance of $50 \mathrm{~cm}$. The experimental task was presented in six block conditions, comprising of two levels of difficulty (3 circles: low difficulty or 7 circles: high difficulty) and three reward conditions (no reward, small reward and high reward) and using a Latin-square design. The six block conditions were: 3 circles (i.e. low difficulty) with no reward, 3 circles (i.e. low difficulty) with small reward, 3 circles (i.e. low difficulty) with high reward, 7 circles (i.e. high difficulty) with no reward, 7 circles (i.e. high difficulty) with small reward 7 circles (i.e. high difficulty) with high reward. Each block conditions consisted of
12 trials each and the order of the blocks were pseudorandomized.

At the onset of each trial (see Fig. 1), a visual cue (1500 ms) was presented (low difficulty: 3 circles; or high difficulty: 7 circles), along with the monetary reward associated with performance (a blank screen for no reward trials or " $\$ \$$ ” for reward trials). After the presentation of a fixation cross $(500 \mathrm{~ms})$, participants saw an array of yellow circles ( 3 or 7 circles, $1500 \mathrm{~ms}$ ). A fixation cross (3000 ms) was presented before the visual target $(1500 \mathrm{~ms})$. The visual target (a green circle) was displayed in any position on the screen and signalled that the participant should decide as quickly as possible whether this circle was in the same position as one of the circles presented previously. After response execution and a variable jittered interstimulus interval (ISI; 0 or $2000 \mathrm{~ms}$ ), the feedback screen $(1000 \mathrm{~ms})$ informed the participant of his or her winnings (blank screen for no reward trials; "1 CHF" for highreward trials and "0.10 CHF" for small-reward trials), followed by a feedback screen $(1000 \mathrm{~ms})$ indicating the cumulative amount of earned money (reward trials) or a blank screen (no reward trials). Correct responses were associated with monetary gains ("1 CHF" for high-reward trials and " $0.10 \mathrm{CHF"} \mathrm{for} \mathrm{small-reward} \mathrm{trials)} \mathrm{in}$ the reward condition. Correct responses were not associated with monetary gains $(0 \mathrm{CHF})$ in the no reward condition. The monetary reward increased according to the difficulty of the task, i.e., CHF 0.10 in the block with three circles vs. CHF 1 in the block with seven circles. Each level of difficulty comprised 12 trials. We asked the participants to rate their momentary mood using a visual analogue scale from 0 (bad mood)- 100 (good

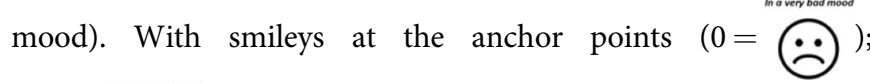
$(100=(\because))$. Only the schematic faces were seen by the participants. The participants rated their momentary mood on a 


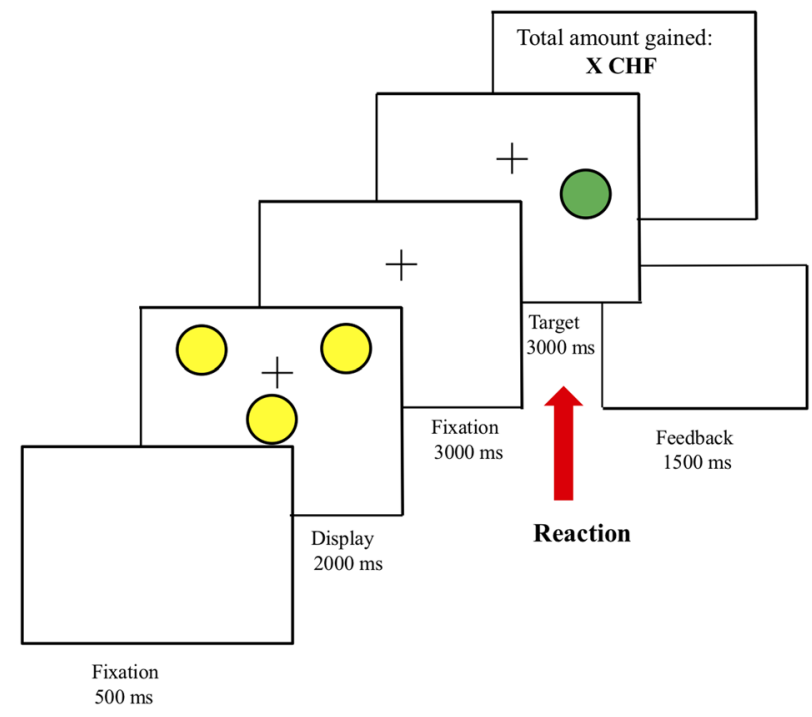

Fig. 1 Schematic representation of a trial of the Fribourg Reward Task at low level of difficulty (3 circles). This figure shows the schematic representation of a trial of the reward task at low level of difficulty ( 3 circles). In the first display, an array of yellow circles ( 3 or 7) was presented for $2000 \mathrm{~ms}$ after a fixation time of $500 \mathrm{~ms}$. After a delay of $3000 \mathrm{~ms}$, a green circle appeared, and the subject had $1500 \mathrm{~ms}$ to decide whether the position of the green circle was the same as that of one of the preceding yellow circles. If so, the correct response for participants was to press a button with their right hand. If not, the participants had to press a button with their left hand. After the response time had elapsed, the circle disappeared, and the accumulated amount of money earned appeared on the screen in the reward condition or nothing is shown on the screen in the no reward condition. The reward task also comprised of two levels of difficulty determined by the number of the circles to remember (low; 3 and high; 7). During the reward condition, the participants should earn a monetary reward for every correct response and the reward increased according to the difficulty of the task.

scale of $0-100$ at baseline, at the beginning of the experimental session, and before and after each block for a maximal duration of $20 \mathrm{~s}$. Participants were informed that they would receive the total sum in cash at the end of the scanning session. Participants underwent a training phase before proceeding to the main task. A criterion of $70 \%$ correct responses was chosen to prevent arbitrary guessing and thereby verify understanding of the task and ensure that participants would win similar amounts of money.

Psychometric measures. Anxiety was measured using the Hospital Anxiety and Depression scale (HADS; [Bocéréan and Dupret, 2014; Zigmond and Snaith, 1983]). This is a self-rating scale that consists of 14 items: 7 items measuring symptoms of depression and 7 items measuring symptoms of anxiety. Each item is coded from 0 to 3, yielding a score between 0 and 21 for each scale. This scale was used only for the selection of the participants. In our study, we used only 7 items to measure the symptoms of anxiety for screening purposes. Participants with any symptoms of anxiety (score $\geq 11$ ) were excluded from the study.

Measures of pain. The Symptom Checklist (SCL-27-plus; Hardt, 2008) is a multidimensional assessment instrument for mental health status (Kuss et al., 2017). With 27 items rated on a 5-point Likert-type scale, it consists of five dimensions: depressive, vegetative, agoraphobic, social phobia and pain symptoms, and a global severity index. A lifetime assessment of depressive symptoms and a screening question for suicidality are also included. Previous studies reported significant pain symptoms in university students using the SCL-27 (Conley et al., 2017; Recabarren et al., 2019).

Participants rated the following pain symptoms: headaches, chest pain, muscle cramps, muscle aches, arm/leg pain, and lower back pain for 0 "never" to 4 "very often" on a pain subscale depending on how often these symptoms occur in general. A value of " 0 " stood for never, " 1 " stood for 1-2 days, " 2 " for 3-7 days, " 3 ” for 8-12 days, and " 4 ” for 13-14 days. A score $\geq 1.77$ indicates physical symptoms of pain according SCL-27 (Hardt, 2008). The Cronbach's alpha coefficient in this study was 0.73 .

Data analysis. Analyses were calculated using IBM SPSS Inc. 25. The normality tests were performed, and the data were found to be normally distributed using Shapiro-Wilk Test $W(79)=0.98$, $p=0.75$. Baseline mood ratings were compared among the groups using a one-way ANOVA. As we did not find any significant group differences at baseline, these ratings were not included into the further analyses of mood as proposed in Martin-Soelch et al., (2009) results. We also performed exploratory analyses comparing the mean mood ratings between groups in the no reward conditions to test the specificity of our results. In order to test the influence of reward on mood in participants in the sub-clinical pain group and in the control group, a repeated-measures ANOVA was conducted, using mood as the dependent variable, with the following factors: groups (with pain symptoms and without clinically significant pain symptoms) as a between group factor, reward conditions (no, low, and high), and levels of difficulty (low and high) as within group factors. Two additional mixed ANOVAs using the same factors were applied using response accuracy and reaction time as the dependent variables with the same factors to test the effect of reward on performance and to compare the possible performance differences between the two groups of participants.

In addition, we postulated that there would be significant positive correlation between mood ratings and monetary gains in the rewarded conditions in the control group, but not in the subclinical group. To test this hypothesis, Pearson product-moment correlation between average mood scores and average monetary wins over all reward conditions was performed in each group of subjects separately according to the similar studies done previously (Kalebasi et al., 2015; Martin-Soelch et al., 2009). To adjust for the multiple comparisons, a Bonferroni correction was implemented. Only $p$-values $<0.025 \quad(0.05 / 2)$ were deemed significant. Additional explorative correlations were performed between the mean mood scores and the response accuracy for each condition separately. The corrected $p$-value for these explorative analyses was $0.013(0.05 / 4)$.

\section{Results}

Reward and mood. Average mood scores in the reward and no reward condition are summarized in Table 2. Baseline mood scores were $74.27 \pm 20.90$ (mean \pm SD) for the control group and $73.66 \pm 14.44$ for the sub-clinical pain group. The results of the one-way ANOVA showed no significant difference in mood between groups at the baseline $\left(F_{1,79}=2.09, p=0.13\right)$. We also performed exploratory analyses comparing the mean mood ratings between groups and the no reward conditions and no significant differences were found $\left(F_{10,68}=0.309, p=0.998\right)$. The results of the repeated-measures ANOVA of mood showed no significant interaction effect between groups and levels of difficulty $\left(F_{1,77}=0.056, \mathrm{MSE}=0.798, p=0.81, \eta_{\mathrm{p}}^{2}=0.001\right)$. A significant main effect was seen only for the factor of reward $\left(F_{2,154}=4.159, \quad \mathrm{MSE}=93.48, \quad p=0.004\right.$ significant at 0.01 , $\left.\eta_{\mathrm{p}}^{2}=0.05\right)$. Participants reported higher mood scores in response to high reward $(M=75.80, \mathrm{SD}=17.98)$ compared to small 
reward $(M=74.33, \mathrm{SD}=17.68)$. No significant main effect was seen for difficulty $\left(F_{1,77}=3.477, \quad \mathrm{MSE}=49.86, \quad p=0.027\right.$, $\left.\eta_{\mathrm{p}}^{2}=0.043\right)$, groups $\left(F_{1,77}=0.447, \quad \mathrm{MSE}=856.632, p=0.5\right.$, $\left.\eta_{\mathrm{p}}^{2}=0.006\right)$, for the interactions between difficulty and reward $\left(F_{2,154}=0.25, \quad \mathrm{MSE}=6.57, \quad p=0.78, \quad \eta_{\mathrm{p}}^{2}=0.003\right)$, between groups and reward $\left(F_{2,154}=1.453, \mathrm{MSE}=32.655, p=0.24\right.$, $\left.\eta_{\mathrm{p}}^{2}=0.019\right)$ nor between difficulty, groups and reward $\left(F_{2,154}=0.587, \mathrm{MSE}=15.45, p=0.56, \eta_{\mathrm{p}}^{2}=0.008\right)$.

Correlations between mood and reward. In the control group, a significant positive correlation was found between average mood scores and average monetary wins across conditions $\left(r_{38}=0.42\right.$, $p=0.008$, Bonferroni-corrected). However, in the sub-clinical group, no significant correlation was found between average mood scores and average monetary wins across conditions $\left(r_{37}=0.12, p=0.46\right.$, Bonferroni-corrected) (shown in Fig. 2).

Reward and performance. Results for accuracy of responses for each level of difficulty are summarized in Table 3.

The mixed ANOVA of accuracy showed no significant effect for the interaction between groups and levels of difficulty

\section{Table 2 Means and standard errors for mood scores in the reward and no reward conditions for each level of difficulty of the task.}

\begin{tabular}{|c|c|c|c|c|c|}
\hline \multirow[t]{2}{*}{ Group } & \multirow[t]{2}{*}{$\boldsymbol{N}$} & \multirow{2}{*}{$\begin{array}{l}\text { Difficulty } \\
\text { (number } \\
\text { of circles) }\end{array}$} & \multicolumn{2}{|c|}{ Reward conditions } & \multirow{2}{*}{$\begin{array}{l}\text { No reward } \\
\text { conditions }\end{array}$} \\
\hline & & & Small & High & \\
\hline Sub- & 39 & 3 & $73.11 \pm 2.69$ & $74.92 \pm 2.48$ & $72.17 \pm 3.12$ \\
\hline Clinical & & 7 & $73.07 \pm 2.56$ & $72.37 \pm 2.61$ & $72.5 \pm 2.60$ \\
\hline Control & 40 & 3 & $76.23 \pm 2.93$ & $76.66 \pm 3.20$ & $76.43 \pm 3.07$ \\
\hline & & 7 & $74.9 \pm 3.24$ & $75.51 \pm 3.13$ & $74.55 \pm 3.18$ \\
\hline
\end{tabular}

This table demonstrates the scores of both the groups. The sub-clinical group showed lower mood scores than the control group at both levels of difficulty (low and high) of the reward conditions (small and high)
$\left(F_{1,77}=2.092, \mathrm{MSE}=0.023, p=0.15, \eta_{\mathrm{p}}^{2}=0.026\right)$. A significant main effect was seen for the factor of reward $\left(F_{2,154}=153.261\right.$, $\mathrm{MSE}=1.98, p=0.00$ significant at $\left.0.01, \eta_{\mathrm{p}}^{2}=0.666\right)$. Performance was significantly more accurate in the high reward condition $(M=0.91, \mathrm{SD}=0.09)$ compared to the small reward condition $(M=0.67, \mathrm{SD}=0.17)$. There was also a significant main effect seen for the factor of difficulty $\left(F_{1,77}=76.90\right.$, $\mathrm{MSE}=0.846, p=0.003$ significant at $\left.0.01, \eta_{\mathrm{p}}^{2}=0.500\right)$, with higher accuracy in the low difficulty level $(M=0.91, \mathrm{SD}=0.86)$ than in the high difficulty level $(M=0.67, \mathrm{SD}=0.14)$. No significant main effect was seen for groups $\left(F_{1,77}=0.229\right.$, $\left.\mathrm{MSE}=0.009, p=0.633, \eta_{\mathrm{p}}^{2}=0.003\right)$. A significant effect was seen for the interaction between difficulty and reward $\left(F_{2,154}=43.534, \quad \mathrm{MSE}=0.541, \quad p=0.008\right.$ significant at 0.01 , $\left.\eta_{\mathrm{p}}^{2}=0.361\right)$ but not for the interaction between groups and reward $\left(F_{2,154}=0.416, \mathrm{MSE}=0.005, p=0.66, \eta_{\mathrm{p}}^{2}=0.005\right)$ or between difficulty, groups and reward $\left(F_{2,154}=0.075\right.$, $\left.\mathrm{MSE}=0.001, p=0.93, \eta_{\mathrm{p}}^{2}=0.001\right)$.

The mixed ANOVA of reaction time showed no significant effect for the interaction between groups and levels of difficulty $\left(F_{1,77}=0.749, \mathrm{MSE}=3.549 \mathrm{E}+10, p=0.39, \eta_{\mathrm{p}}^{2}=0.010\right)$, factor of reward $\left(F_{2,154}=0.007, \mathrm{MSE}=286,757,154, p=0.99, \eta_{\mathrm{p}}^{2}=0.000\right)$,

Table 3 Means and standard errors for accuracy of responses in the reward and no reward conditions for each level of difficulty of the task.

\begin{tabular}{|c|c|c|c|c|c|}
\hline \multirow{2}{*}{ Group } & \multirow[t]{2}{*}{$\mathbf{N}$} & \multirow{2}{*}{$\begin{array}{l}\text { Difficulty } \\
\text { (number } \\
\text { of circles) }\end{array}$} & \multicolumn{2}{|c|}{ Reward conditions } & \multirow{2}{*}{$\begin{array}{l}\text { No reward } \\
\text { conditions }\end{array}$} \\
\hline & & & Small & High & \\
\hline \multirow{4}{*}{$\begin{array}{l}\text { Sub- } \\
\text { clinical } \\
\text { Control }\end{array}$} & 39 & 3 & $0.88 \pm 0.017$ & $0.92 \pm 0.012$ & $0.89 \pm 0.016$ \\
\hline & & 7 & $0.68 \pm 0.021$ & $0.66 \pm 0.20$ & $0.66 \pm 0.027$ \\
\hline & 40 & 3 & $0.89 \pm 0.018$ & $0.90 \pm 0.015$ & $0.89 \pm 0.018$ \\
\hline & & 7 & $0.69 \pm 0.022$ & $0.69 \pm 0.023$ & $0.68 \pm 0.026$ \\
\hline
\end{tabular}

\section{Correlations between mean mood scores and monetary wins (CHF)}

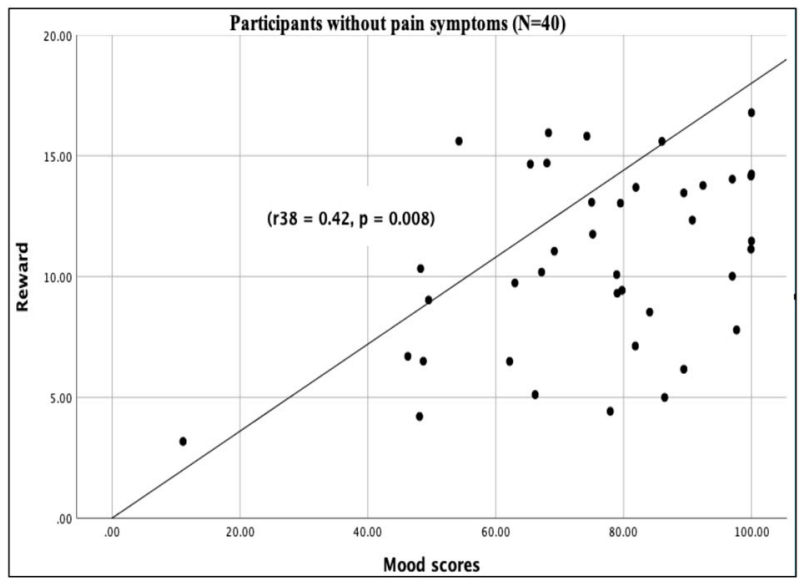

(a)

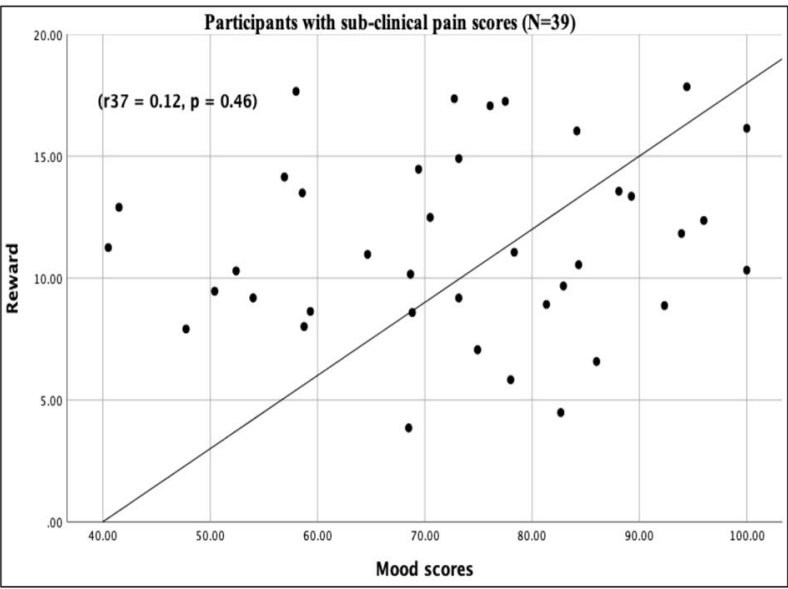

(b)

Fig. 2 Correlations between the mean mood scores and the amount of monetary reward received. The following different figures demonstrate the correlations between the mean mood scores and the amount of monetary reward received during the two levels of difficulty (high and low). The value of the $y$-axis shows the sum win (in CHF) obtained by adding the monetary wins over all reward conditions with high and low difficulty. The subjects as represented as dots $(\bullet)$. a Correlation between mean mood scores and the amount of monetary reward received in the control group without clinically significant pain symptoms of pain $(N=40)$. The results indicate that there was a significant positive correlation found $\left(r_{38}=0.42, p=0.008\right)$.

b Correlation between mean mood scores and the amount of monetary reward received in the sub-clinical group with the symptoms of pain $(N=39)$. The results indicate that there was no significant correlation found $\left(r_{37}=0.12, p=0.46\right)$. 
factor of difficulty $\left(F_{1,77}=0.874, \quad \mathrm{MSE}=4.136 \mathrm{E}+10, p=0.87\right.$, $\left.\eta_{\mathrm{p}}^{2}=0.011\right)$, groups $\left(F_{1,77}=2.32, \mathrm{MSE}=2.491 \mathrm{E}+10, p=0.13\right.$, $\left.\eta_{\mathrm{p}}^{2}=0.029\right)$ nor for the interaction between difficulty and reward $\left(F_{2,154}=1.750, \mathrm{MSE}=6.549 \mathrm{E}+10, p=0.178, \eta_{\mathrm{p}}^{2}=0.022\right)$, groups and reward $\quad\left(F_{2,154}=0.565, \quad \mathrm{MSE}=2.386 \mathrm{E}+10, \quad p=0.57\right.$, $\left.\eta_{\mathrm{p}}^{2}=0.007\right)$ nor between difficulty, groups and reward $\left(F_{2,154}=0.206, M S E=7.708 \mathrm{E}+9, p=0.81, \eta_{\mathrm{p}}^{2}=0.003\right)$ reached the significance.

Correlations between mood and response accuracy. Additional explorative correlations were performed between mean mood scores and response accuracy found significant positive correlations in the control group during the condition with the high level of difficulty $\left(r_{38}=0.32, p=0.04\right)$ but was no more significant after Bonferroni correction was applied for four comparisons, $p<0.013$. During the condition with the low level of difficulty no significant correlation was found $\left(r_{38}=-0.03, p=0.84\right)$. In the sub-clinical pain group, no significant positive correlations were found during the condition with the high level of difficulty $\left(r_{37}=0.03, p=0.88\right)$ and with the low level of difficulty $\left(r_{37}=0.08, p=0.64\right)$.

\section{Discussion}

The main aim of the present study was to investigate the relationship between behavioural and mood responses to monetary rewards between a sub-clinical group reporting clinically significant physical pain symptoms and a control group without any clinically significant physical pain symptoms in everyday life. We hypothesized that the sub-clinical group would show a reduction in the effect of a monetary reward on mood ratings compared to the control group. We used the Fribourg Reward Task (Martin-Soelch et al., 2009), including two levels of difficulty and three reward conditions, in order to test the relationship between monetary reward, mood scores, and performance in the two groups. We also investigated the influence of task difficulty on mood, reward and performance.

Interestingly in the present study, $49 \%$ of the university students tested reported high levels of physical symptoms of pain which is in line with a previous study in a similar sample of students (Recabarren et al., 2019). One of the reasons for this high prevalence of pain symptoms could be that the university students are prone to inactivity for long period of time which is characterized by prolonged sitting (FelezNobrega et al., 2018).

With regard to our hypothesis that the effect of reward on mood and performance would be reduced in participants with sub-clinical pain, our ANOVA results did not show any significant interaction between monetary wins, levels of difficulty and groups neither for mood scores nor for the outcomes related to performance, i.e., response accuracy and reaction time. These results suggest that the significant interaction reported by several studies (Navratilova et al., 2016; Loggia et al., 2014; Seixas et al., 2016) in relation to pain and reward might be mostly related to individuals with chronic pain and these associations are not seen in the sub-clinical population. The significant interaction between reward and levels of difficulty for the outcomes related to performance replicate previous findings obtained with this task (Gaillard et al., 2019).

Our results showed a significant positive correlation between mood ratings and monetary wins in the control group, but not significant in the sub-clinical group in agreement with our hypothesis. These results suggest that there is a reduced association between monetary reward and mood in the sub-clinical group. This is in agreement with previous studies conducted on students with chronic pain that found reduced reward functioning and mood responses as compared to the healthy controls (Berger et al., 2014) as well as with findings obtained in chronic pain patients (Treadway and Zald, 2011). To our knowledge, these results are the first to suggest that changes in the reward-pain interaction can be identified in sub-clinical pain population, and therefore provide information about the effect of pain on the processing of reward without the limitation of medication and treatment. In addition, our finding of a blunted association between mood and reward in a sub-clinical population might yield first insights to develop preventive intervention. In that context, a former study showed that a stress prevention in University students could significantly reduce self-reported pain symptoms for instance (Recabarren et al., 2019). It could be also beneficial to test in future studies the preventive effect of interventions that showed a bettering of reward mechanisms in chronic pain patients, such as Mindfulness-Oriented Recovery Enhancement (MORE) training for instance (Garland, 2020) in university students reporting significant pain symptoms.

Limitations. Some limitations merit attention. First, the measurement of pain based only on the Symptom Checklist27-plus (Hardt, 2008) is certainly a limitation of the present study and the use of self-report instruments can lead to memory bias and greater subjectivity in the responses. Especially, the length of our online questionnaires may have led to less accurate answers due to fatigue, even though the participants could take breaks. Second, the sample consisted mainly of female students from the university, which limits the generalization of our results. Students had an additional motivation factor for their participation: they could receive experimental points instead of financial reimbursement in order to meet the requirements of their bachelor studies.

In conclusion, our findings provide very promising evidence of the interaction between pain and reward, and that its effects can also be found in a sub-clinical population. The investigation of a sub-clinical population might help to disentangle the complex relationship between pain and reward without the limitation of medication, treatment, adaptation to pain and comorbidities associated with the investigation of participants with chronic pain. This relationship in a sub-clinical population provides first insight into the development of preventive interventions. More research is needed to study the pain-reward interaction in healthy participants with sub-clinical pain symptoms and the continuum between sub-clinical and clinical pain.

\section{Data availability}

The datasets analysed during the current study are deposited in Dataverse repository (https://doi.org/10.7910/DVN/FFHIIB).

Received: 28 March 2021; Accepted: 30 December 2021; Published online: 25 January 2022

\section{Note}

1 The participants studying psychology were given experimental points as compensation as part of their bachelor's curriculum.

\section{References}

American Psychiatric Association (2013) Diagnostic and statistical manual of mental disorders: DSM-5. Arlington, VA

Bair MJ, Robinson RL, Katon W, Kroenke K (2003) Depression and pain comorbidity: a literature review. Arch Intern Med 163(20):2433-2445 
Becker S, Gandhi W, Elfassy NM, Schweinhardt P (2013) The role of dopamine in the perceptual modulation of nociceptive stimuli by monetary wins or losses. Eur J Neurosci 38:3080-3088. https://doi.org/10.1111/ejn.12303

Becker S, Gandhi W, Schweinhardt P (2012) Cerebral interactions of pain and reward and their relevance for chronic pain. Neurosci Lett 520:182-187. https://doi.org/10.1016/j.neulet.2012.03.013

Berger SE, Baria AT, Baliki MN, Mansour A, Herrmann KM, Torbey S, Huang L, Parks EL, Schnizter TJ, Apkarian AV (2014) Risky monetary behavior in chronic back pain is associated with altered modular connectivity of the nucleus accumbens. BMC Res Notes 7(1):1-14

Bocéréan C, Dupret E (2014) A validation study of the Hospital Anxiety and Depression Scale (HADS) in a large sample of French employees. BMC Psychiatry 14(1):354

Conley AH, Overstreet CM, Hawn SE, Kendler KS, Dick DM, Amstadter AB (2017) Prevalence and predictors of sexual assault among a college sample. J Am College Health 65(1):41-49

Dersh J, Polatin PB, Gatchel RJ (2002) Chronic pain and psychopathology: research findings and theoretical considerations. Psychosom Med 64(5):773-786

Felez-Nobrega M, Hillman CH, Dowd KP, Cirera E, Puig-Ribera A (2018) ActivPAL $^{\mathrm{mox}}$ determined sedentary behaviour, physical activity and academic achievement in college students. J Sports Sci 36(20):2311-2316

Fields HL (2006) A motivation-decision model of pain: the role of opioids. In Proceedings of the 11th world congress on pain (pp. 449-459). Seattle: IASP press

Gaillard C, Guillod M, Ernst M, Torrisi S, Federspiel A, Schoebi D, Recabarren RE, Ouyang X, Mueller-Pfeiffer C, Horsch A (2019) Striatal responsiveness to reward under threat-of-shock and working memory load: a preliminary study. Brain Behav 9(10):e01397

Gandhi W, Becker S, Schweinhardt P (2014) The influence of pain on reward processing: current literature and prospects. In: Neurobiological studies of addiction in chronic pain states. Springer, New York, pp. 31-48

Gandhi W, Becker S, Schweinhardt P (2013) Pain increases motivational drive to obtain reward, but does not affect associated hedonic responses: a behavioural study in healthy volunteers. Eur J Pain 17(7):1093-1103

Garland EL (2020) Psychosocial intervention and the reward system in pain and opioid misuse: new opportunities and directions. Pain 161(12):2659-2666

Gravani S, Matiatou M, Nikolaidis PT, Menenakos E, Zografos CG, Zografos G, Albanopoulos K (2021) Anxiety and Depression Affect Early Postoperative Pain Dimensions after Bariatric Surgery. J Clin Med 10(1):53

Gupta R (2019) Positive emotions have unique capacity to capture attention. Prog Brain Res 16:144-149

Gupta R, Raymond JE, Vuilleumier P (2019) Priming by motivationally salient distractors produces hemispheric asymmetries in visual processing Psychol Res $83: 1798-1807$

Hardt J (2008) The symptom checklist-27-plus (SCL-27-plus): a modern conceptualization of a traditional screening instrument. GMS Psycho-Social Med, 5:Doc08

Hidi S (2016) Revisiting the role of rewards in motivation and learning: implications of neuroscientific research. Educ Psychol Rev 28(1):61-93

Kalebasi N, Kuelen E, Schnyder U, Schumacher S, Mueller-Pfeiffer C, Wilhelm FH, Athilingam J, Moergeli H, Martin-Soelch C (2015) Blunted responses to reward in remitted post-traumatic stress disorder. Brain Behav 5(8):e00357

Kim M, Mawla I, Albrecht DS, Admon R, Torrado-Carvajal A, Bergan C, Protsenko E, Kumar P, Edwards RR, Saha A (2020) Striatal hypofunction as a neural correlate of mood alterations in chronic pain patients. Neuroimage 211:116656

Kuss DJ, Dunn TJ, Wölfling K, Müller KW, Hędzelek M, Marcinkowski J (2017) Excessive Internet use and psychopathology: the role of coping. Clin Neuropsychiatry 14(1):73-81

Lakens D (2013) Calculating and reporting effect sizes to facilitate cumulative science: a practical primer for $t$-tests and ANOVAs [Review]. Front Psychol 4(863). https://doi.org/10.3389/fpsyg.2013.00863

Ledermann K, Martin-Sölch C (December 19th 2018). Chronic Pain, Dopamine and Depression: Insights from Research on Fibromyalgia, Chronic Pain Physiopathology and Treatment, Vicente Vanaclocha and Nieves SaizSapena, IntechOpen, https://doi.org/10.5772/intechopen.82576. Available from: https://www.intechopen.com/chapters/64845

Ledermann K, Jenewein J, Sprott H, Hasler G, Schnyder U, Warnock G, Johayem A, Kollias S, Buck A, Martin-Soelch C (2017) Altered dopamine responses to monetary rewards in female fibromyalgia patients with and without depression: A [11C] raclopride bolus-plus-infusion PET study. Psychother Psychosom 86(3):181-182

Leknes S, Tracey I (2008) A common neurobiology for pain and pleasure. Nat Rev Neurosci 9(4):314-320

Liu X, Wang N, Gu L, Guo J, Wang J, Luo F (2019) Reward processing under chronic pain from the perspective of "liking" and "wanting": a narrative review. Pain Res Manag 2019:6760121. https://doi.org/10.1155/2019/6760121
Loggia ML, Berna C, Kim J, Cahalan CM, Gollub RL, Wasan AD, Napadow V (2014) Disrupted brain circuitry for pain-related reward/punishment in fibromyalgia. Arthritis Rheumatol 66(1):203-212

Martin-Soelch C, Kobel M, Stoecklin M, Michael T, Weber S, Krebs B, Opwis K (2009) Reduced response to reward in smokers and cannabis users. Neuropsychobiology 60(2):94-103

Martin-Soelch C, Missimer J, Leenders K, Schultz W (2003) Neural activity related to the processing of increasing monetary reward in smokers and nonsmokers. Eur J Neurosci 18(3):680-688

Martucci KT, Borg N, MacNiven KH, Knutson B, Mackey SC (2018) Altered prefrontal correlates of monetary anticipation and outcome in chronic pain. Pain 159(8):1494

Murayama K (2019) A reward-learning framework of knowledge acquisition: An integrated account of curiosity, interest, and intrinsic-extrinsic rewards. https://doi.org/10.31219/osf.io/zey4k

Mikita N, Simonoff E, Pine DS, Goodman R, Artiges E, Banaschewski T, Bokde A, Bromberg U, Büchel C, Cattrell A (2016) Disentangling the autism- anxiety overlap: fMRI of reward processing in a community-based longitudinal study Translational psychiatry 6(6):e845

Navratilova E, Morimura K, Xie JY, Atcherley CW, Ossipov MH, Porreca F (2016) Positive emotions and brain reward circuits in chronic pain. J Comp Neurol524(8):1646-1652

Piccolo M, Milos G, Bluemel S, Schumacher S, Müller-Pfeiffer C, Fried M, Ernst M, Martin-Soelch C (2019) Food vs. money? Effects of hunger on mood and behavioral reactivity to reward in anorexia nervosa. Appetite 134:26-33

Recabarren RE, Gaillard C, Guillod M, Martin-Soelch C (2019) Short-term effects of a multidimensional stress prevention program on quality of life, well-being and psychological resources. A randomized controlled trial. Front Psychiatry 10:88

Rizvi SJ, Gandhi W, Salomons T (2021) Reward processing as a common diathesis for chronic pain and depression. Neurosci Biobehav Rev 127:749-760. https://doi.org/10.1016/j.neubiorev.2021.04.033

Seixas D, Palace J, Tracey I (2016) Chronic pain disrupts the reward circuitry in multiple sclerosis. Eur J Neurosci 44(3):1928-1934

Salazar A, Dueñas M, Mico JA, Ojeda B, Agüera-Ortiz L, Cervilla JA, Failde I (2013) Undiagnosed mood disorders and sleep disturbances in primary care patients with chronic musculoskeletal pain. Pain Med 14(9):1416-1425

Sheehan DV, Lecrubier Y, Sheehan KH, Amorim P, Janavs J, Weiller E, Hergueta T, Baker R, Dunbar GC (1998) The Mini-International Neuropsychiatric Interview (MINI): the development and validation of a structured diagnostic psychiatric interview for DSM-IV and ICD-10. J Clin Psychiatry 59(20):22-33

Treadway MT, Zald DH (2011) Reconsidering anhedonia in depression: lessons from translational neuroscience. Neurosci Biobehav Rev 35(3):537-555

Turner, AP, Jensen, MP, Day, MA, Williams, RM (2021) Behavioral activation and behavioral inhibition: An examination of function in chronic pain. Rehabilitation psychology 66(1):57

White NM (2011) Reward: what is it? How can it be inferred from behavior? In Gottfried JA, editor. Neurobiology of Sensation and Reward. Boca Raton (FL): CRC Press/Taylor \& Francis. Chapter 3, pp 45-60. Available from: https://www.ncbi.nlm.nih.gov/books/NBK92792

Zigmond AS, Snaith RP (1983) The hospital anxiety and depression scale. Acta Psychiatr Scand 67(6):361-370

\section{Competing interests}

The authors declare no competing interests.

\section{Ethical approval}

This study was performed in line with the principles of the Declaration of Helsinki. Approval was granted by the internal review board (2017/IRB 334A) at the Department of Psychology at the University.

\section{Informed consent}

The participants were thoroughly informed about the study and gave their written consent according to the Declaration of Helsinki. The privacy rights of participants were always observed during our study.

\section{Additional information}

Correspondence and requests for materials should be addressed to Tanya Tandon.

Reprints and permission information is available at http://www.nature.com/reprints

Publisher's note Springer Nature remains neutral with regard to jurisdictional claims in published maps and institutional affiliations. 
(c) (i) Open Access This article is licensed under a Creative Commons Attribution 4.0 International License, which permits use, sharing, adaptation, distribution and reproduction in any medium or format, as long as you give appropriate credit to the original author(s) and the source, provide a link to the Creative Commons license, and indicate if changes were made. The images or other third party material in this article are included in the article's Creative Commons license, unless indicated otherwise in a credit line to the material. If material is not included in the article's Creative Commons license and your intended use is not permitted by statutory regulation or exceeds the permitted use, you will need to obtain permission directly from the copyright holder. To view a copy of this license, visit http://creativecommons.org/ licenses/by/4.0/.

(C) The Author(s) 2022 